\title{
Characterization of Tribological Behaviour of Surface Topographies by Roughness Measurement at the Beginning of the Wear Process
}

\author{
I. Barányi ${ }^{1, *}$ \\ ${ }^{1}$ Óbuda University, Donát Bánki Faculity of Mechanical and Safety \\ Engineering \\ Népszínház street 8., 1088 Budapest, Hungary \\ *e-mail: baranyi.istvan@bgk.uni-obuda.hu
}

Abstract: The examination of the tribological processes can be implement by different methods. In the initial stage of the abrasive wear process, the microtopography of steels drastically changes until it reaches a stable state. This change can be described by different methods. One of the methods is the characterisation with the help of roughness parameters. In this paper validated simulation algorithm has been used to predict the modification of the roughness parameters. Manufactured microtopographies with same arithmetical mean height value can be modelled to the destroying with the help of abrasive worn microtopography. It was found the main roughness parameters named arithmetical mean height, root mean square roughness, skewness and kurtosis modification strongly depending to the manufacturing technology.

Keywords: roughness; wear; initial stage; simulation algorithm

\section{Introduction}

The increasing industrial production demands call forth the tribological design of component surfaces. The contacting surfaces are involved in defining the tribological system. The parameters which describe the surface topographies need to be property defined that we reduce the friction losses of the components and to define the lubrication states. The designing of the surface microtopography is one of 
the most dramatically developing areas of research from the manufacturing and tribology points of view [1].

Kubiak et al. [2] stated that the roughness parameter $R a$ of machined surfaces influenced wear intensity and the friction coefficient. In their measurements of fretting tests found to the activation energy is increasing for smoother surfaces and according to the conclusion the lower initial roughness reduces the wear rate and increase the coefficient of friction.

Xin Pei et al. [3] through numerical simulation, the influence of surface topography, load, slide-to-roll ratio on wear and the evolution of surfaces have been studied and found the early stage of the running in process the wear track deeper in the sides than in the middle and the coefficients of friction is radically decrease in the beginning of the estimation process.

Horváth et al. [4] draws attention to the importance of amplitude parameters named skewness and kurtosis and found connections between these parameters and the circumstances of the cutting process, including edge geometry, tool material, workpiece material, and cutting parameters.

Czifra et al. [5] and Palásti-Kovács et al. [6] searched for techniques to describe topography in their work in order to describe manufactured and abraded surfaces. In addition to traditionally applied parameters, their work involves evaluations based on fractal, slicing algorithm, peak curvature, and steepness distribution and they examine the applicability of each technique.

Reizer, R [7] simulate and measured the roughness microtopography modification in a case of mild wear process. The test ring has been made by honing process and the authors found the $S k u$ surface roughness parameter helps to describe the surface modification.

Kovalev et al. [8] use simulated surface microtopographies and these are worn with abrasion scratches. It has been revealed that the prediction of worn surface structure and its roughness parameters are possible by using effective surface profile withrespect.

Based on the literature it can be stated that the phase of initial wear, to be characterized by changes in microtopography parameters applied in roughness measurements, is not fully elaborated in the literature. Therefore, a truncation algorithm [9] has been used with different manufactured surface microtopographies to model the wear process, validated by measurement results. The model can be used for forecasting changes in roughness parameters $S a, S q, S s k$, and $S k u$ subject to given abrasion conditions until the destruction of the microtopography produced. 


\section{Experimental}

\subsection{Truncation algorithm}

In case of microtopographies, the truncation algorithm can be used for examining the progressive destruction of the peak zone by roughness parameters. The algorithm uses the Abbott -Firestone curve to determine the truncation height and it is patched with abrasion scratches. With the help of this simulation we can give a "virtual" microtopography which has been made with the help of truncated measuring data of the manufactured microtopography and worn microtopography. The model can be validated in [9].

In the results of the algorithm the (1) to (4) parameters calculated and the virtual topographies have been got.

$$
\begin{aligned}
S a & =\frac{1}{n x \cdot n y} \sum_{i=1}^{n x} \sum_{j=1}^{n y}|Z(i, j)| \\
S q & =\sqrt{\frac{1}{n x \cdot n y} \sum_{i=1}^{n x} \sum_{j=1}^{n y} Z(i, j)^{2},} \\
S s k & =\frac{1}{S q^{3}} \frac{1}{n x \cdot n y} \sum_{i=1}^{n x} \sum_{j=1}^{n y} Z(i, j)^{3} \\
S k u & =\frac{1}{S q^{4}} \frac{1}{n x \cdot n y} \sum_{i=1}^{n x} \sum_{j=1}^{n y} Z(i, j)^{4}
\end{aligned}
$$

where:

- $n x$ : number of the measured points in direction $\mathrm{x}$,

- ny: number of the measured points in direction $\mathrm{y}$,

- $Z(i, j)$ : eight coordinates of the $(\mathrm{i}, \mathrm{j})$ pint in micrometres,

- $S a$ : average roughness,

- $S q$ : root mean square roughness,

- Ssk: skewness,

- $\quad S k u$ : kurtosis.

\subsection{Test pieces}

The test pieces which represents the different manufacturing technology were roughness comparator machined by turning (Fig.1), milling (Fig. 2), grinding (Fig. 3 ) and spark erosion (Fig. 4). All the comparator theoretical arithmetical mean height 
$\mathrm{S} \mathrm{Sa}$ ) roughness value was 1.6 micrometres. The microtopographies of the test pieces has been shown in Fig. 1 to Fig. 4 and Table 1. summarize the value of the investigated roughness parameters.

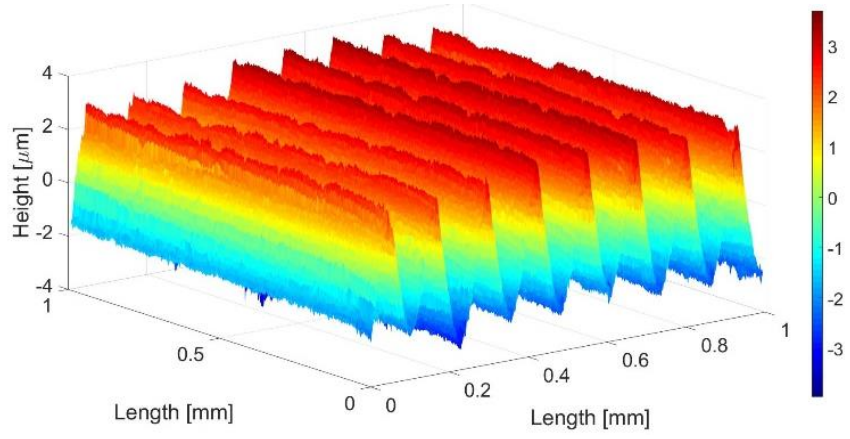

Figure 1. Turned surface microtopography

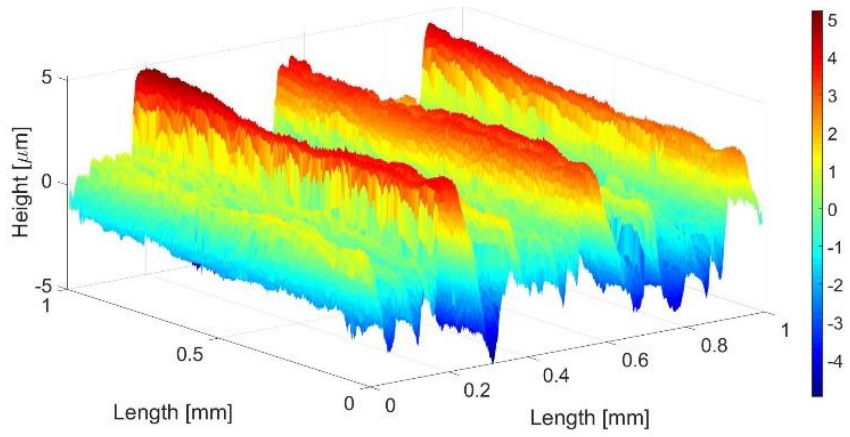

Figure 2. Milled surface microtopography

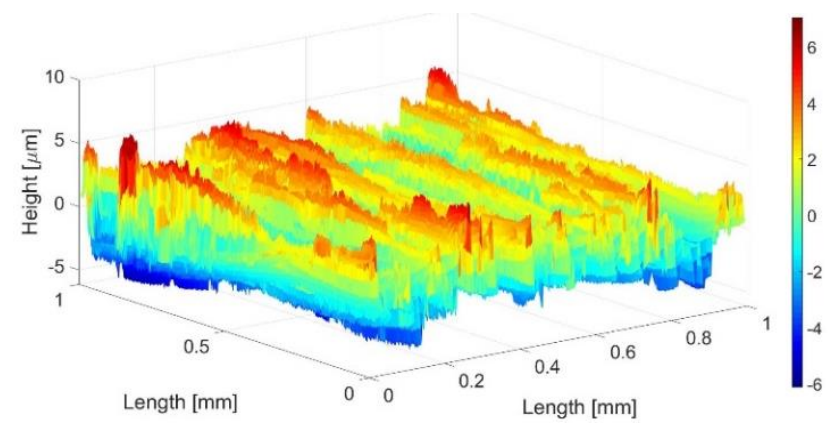

Figure 3. Grinded surface microtopography 


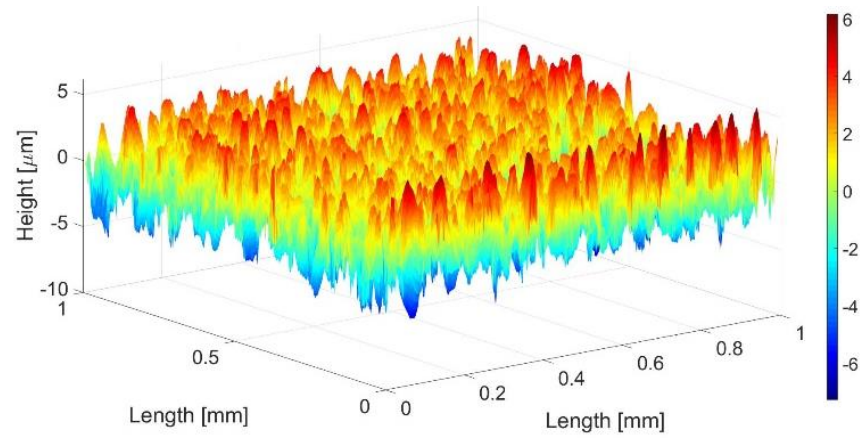

Figure 4. Spark eroded surface microtopography

Table 1. Roughness values of the test pieces

\begin{tabular}{|c|c|c|c|c|}
\hline & Turned & Milled & Grinded & Spark eroded \\
\hline $\mathrm{Sa}[\mathrm{mm}]$ & 1.59 & 1.559 & 1.66 & 1.6360 \\
\hline $\mathrm{Sq}[\mathrm{mm}]$ & 1.799 & 1.929 & 2.05 & 2.0054 \\
\hline Sku [-] & 1.949 & 2.529 & 2.512 & 2.5976 \\
\hline Ssk [-] & 0.245 & 0.453 & 0 & -0.0845 \\
\hline
\end{tabular}

The worn sample had been manufactured from 1.0503 steel in normalized heat treatment state. The manufactured microtopography were destroyed by special running in stage abrasive wear tester developed by Óbuda University and Budapest University of Technology and Economics.

The wear test parameters were:

- $\quad$ pin-on-plate arrangement,

- velocity: $25 \mathrm{~mm} / \mathrm{s}$,

- length: $150 \mathrm{~mm}$,

- contact surface: $30 \mathrm{~mm}$ x $30 \mathrm{~mm}$,

- normal force: $600 \mathrm{~N}$,

- abrasion cloth fineness: 1200 ,

- total wear length: $10800 \mathrm{~mm}$,

- no lubrication used. 
The roughness comparator surfaces and the worn surface was measured by Mahr stylus instrument (typ: FRW 750). The used tip rounding radius was 5 micrometres and with $90^{\circ}$ nose angle.

The measurement sample distance was 2 micrometre and the measuring length was $1 \mathrm{~mm}$ in both directions. Fig. 5 shows the worn microtopography and Table 2 . summarizes its roughness parameters.

Table 2. Roughness values of the worn microtopography

\begin{tabular}{|l|c|c|c|c|}
\hline & $\boldsymbol{S a}[\mathbf{m m}]$ & $\boldsymbol{S q}[\mathbf{m m}]$ & Sku [-] & Ssk [-] \\
\hline Worn sample & 0.4291 & 0.5929 & 14.99 & -2.1552 \\
\hline
\end{tabular}

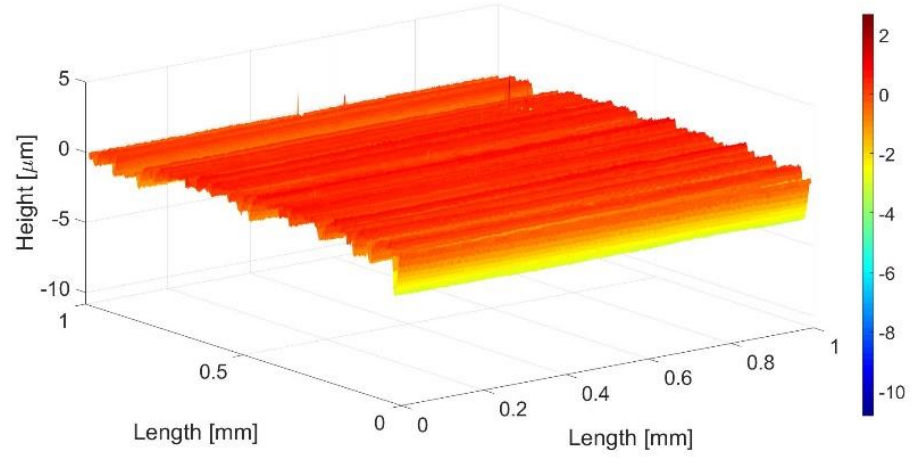

Figure 5. Worn microtopography

\section{Results}

When using the truncation algorithm, the microtopography - and the running-in stage wear process - was divided into 100 parts in $\mathrm{Z}$ direction. Constant material volume was destroyed in every step. Fig. 6 to Fig. 9 show the changes in the parameters defined by the algorithm. 
I. Barányi-Acta Technica Jaurinensis, Vol. 13, No. 2, pp. 151-160, 2020

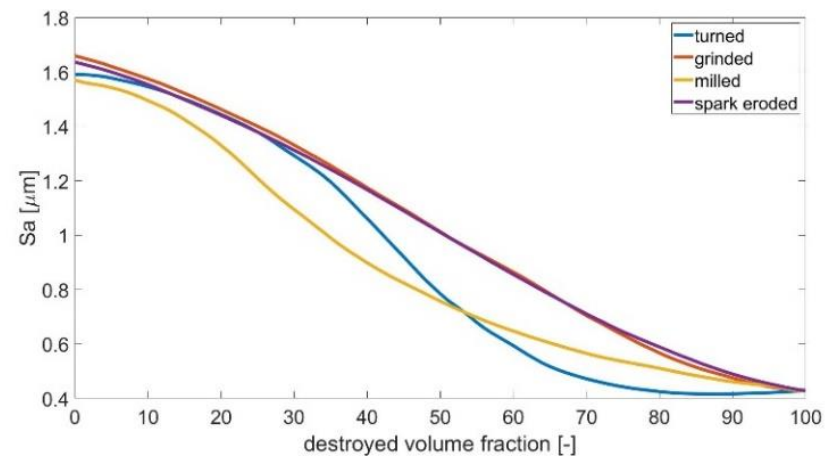

Figure 6. Parameter Sa change in a function of the destroyed volume fraction

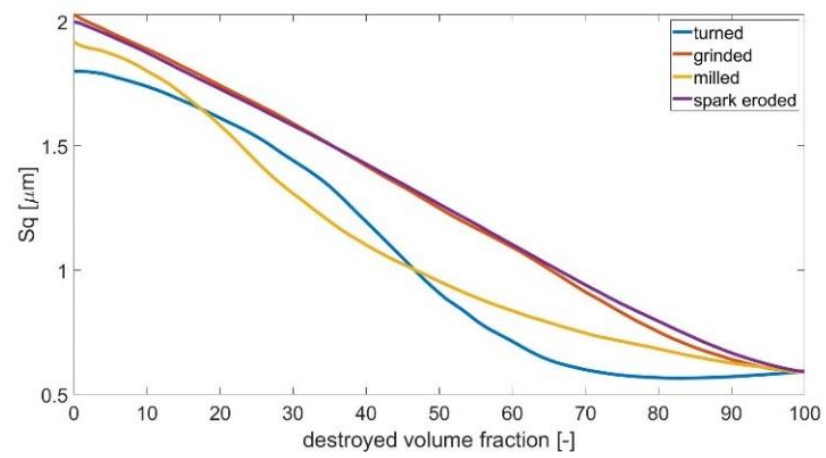

Figure 7. Parameter $S q$ change in a function of the destroyed volume fraction

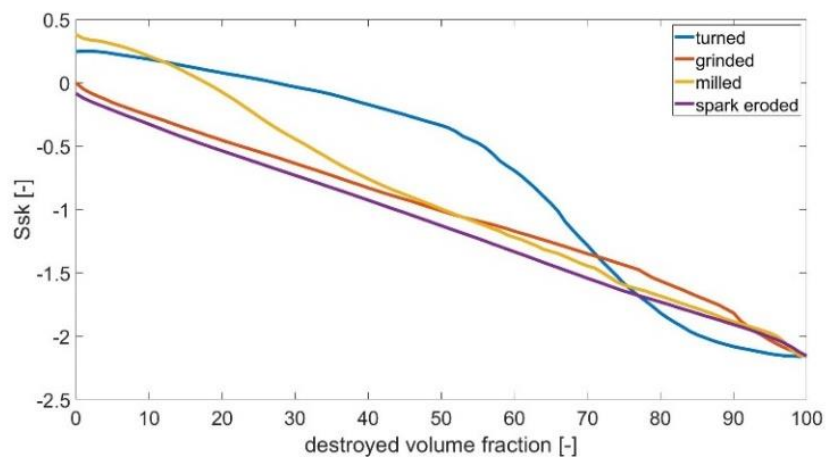

Figure 8. Parameter Ssk change in a function of the destroyed volume fraction 


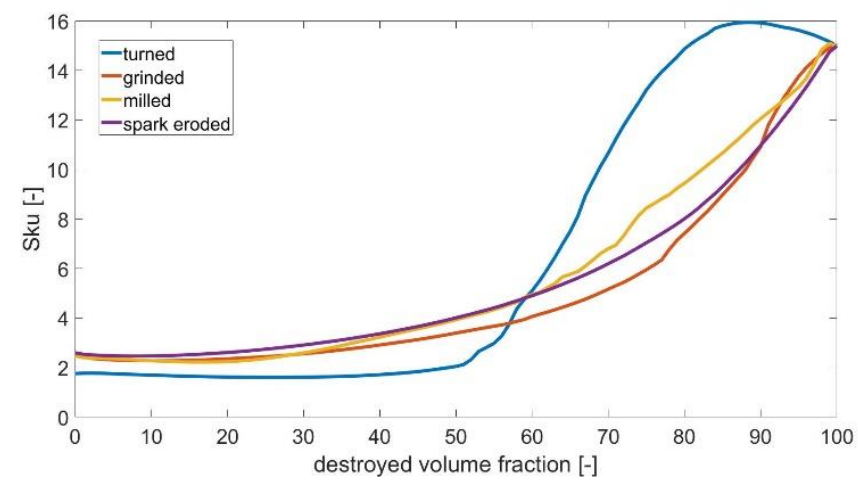

Figure 9. Parameter Sku change in a function of the destroyed volume fraction

For the mathematical description of the results yielded, a modified logistic function (5) was used in the form below by white box method [10].

$$
f=\frac{a x+b}{1+e^{c x+d}}+g
$$

According to the mathematical fitting all curves have been approximated by function (5) with bigger than 0.99 coefficient of determination value.

This mathematical description is of theses curves may be simplified by linear function according to (6). The linear fitting calculation results can be summarized in Table 3 in a perspective of $R^{2}$.

$$
S_{i}=\left(S_{i \text { original }}-S_{i \text { grinded }}\right) \cdot x+S_{i \text { original }}
$$

Where:

- $\quad S_{i}$ represents the surface parameters.

Table 3. Linear fitting coefficients of determination

\begin{tabular}{|c|c|c|c|c|}
\hline & $\boldsymbol{S a} \boldsymbol{R}^{\mathbf{2}}$ & $\boldsymbol{S q} \boldsymbol{R}^{\mathbf{2}}$ & $\boldsymbol{S k u} \boldsymbol{R}^{\mathbf{2}}$ & $\boldsymbol{S s k} \boldsymbol{R}^{\mathbf{2}}$ \\
\hline Turned & 0.8368 & 0.795 & 0.629 & 0.82 \\
\hline Milled & 0.8365 & 0.7985 & 0.2751 & 0.99 \\
\hline Turned & 0.978 & 0.973 & 0.357 & 0.97 \\
\hline Spark eros. & 0.983 & 0.989 & 0.291 & 0.998 \\
\hline
\end{tabular}




\section{Conclusions}

Using the truncation algorithm running in stage wear process simulated with turned, milled, grinded and spark erosion surface microtopography and abrasion destroyed surface microtopography. According to the simulation the main 3D amplitude roughness parameters named average roughness, root mean square roughness skewness and kurtosis are calculated.

The parameter modification curves fitted with two ways. With the help of the 5 parameters logistic function in every case the coefficient of determination value was bigger than 0.99 . The curve fitting with $1^{\text {st }}$ polynomial function according to (6) made different results than the logistic function fitting.

According to Table 3. The average roughness parameters and a root mean square roughness parameters modification in a function of destroyed volume fraction is better described by spark erosion and turned case than turned or milled topography case.

The kurtosis parameter modification is not well described with the $1^{\text {st }}$ degree polynomial. As Fig. 9 shows the first part of the initial stage the curves are semi horizontal (in a 0\%-40\% destroyed volume fraction) and after that started to grow until the end of the initial stage. Only in a case of the turned profile this curve abrupt change makes an opportunity to predicts the end of the initial stage.

The skewness parameter which represents the symmetry of the height distribution curve well described with $1^{\text {st }}$ degree polynomic function in a case of examined milled, grinded and spark eroded microtopographies.

In the future work authors want to describe the roughness topography with other roughness parameters like functional, spatial and hybrid parameters.

\section{References}

[1] A. Mucsi, Analysis of coil break defects, Engineering Failure Analysis 83 (2018) pp. 109-116.

doi: https://doi.org/10.1016/j.engfailanal.2017.09.022

[2] K.J.Kubiak, T.W.Liskiewicz, T.G.Mathiab, Surface morphology in engineering applications: Influence of roughness on sliding and wear in dry fretting, Tribology International 44 (11) (2011) pp. 1427-1432.

doi: https://doi.org/10.1016/j.triboint.2011.04.020

[3] X. Pei, W. Pu, et al., Surface topography and friction coefficient evolution during sliding wear in a mixed lubricated rolling-sliding contact, Tribology 
International 137 (2019) pp. 303-312.

doi: https://doi.org/10.1016/j.triboint.2019.05.013

[4] R. Horváth, Á. Czifra, Á. Drégelyi-Kiss, Effect of conventional and nonconventional tool geometries to skewness and kurtosis of surface roughness in case of fine turning of aluminium alloys with diamond tools, The International Journal of Advanced Manufacturing Technology 78 (2015) pp. 297-304.

doi: https://doi.org/10.1007/s00170-014-6642-5

[5] Á. Czifra, T. Goda, E. Garbayo, Surface Characterisation by Parameter-based Technique, Slicing Method and PSD Analysis, Measurement 44 (2011) pp. 906-916.

doi: https://doi.org/10.1016/j.measurement.2011.02.021

[6] B. Palásti-Kovács, Z. Néder, Á. Czifra, K. Váradi, Microtopography Changes in Wear Process, Acta Polytechnica Hungarica 1 (2004) pp. 108-119.

[7] R. Reizner, et al.. Modeling of Worn Surface Topography Formed in a Low Wear Process, Wear 278-279 (2012) pp. 94-100.

doi: https://doi.org/10.1016/j.wear.2011.12.012

[8] A. Kovalev, et al., A Concept of the Effective Surface Profile to Predict the Roughness Parameters of Worn Surface, Frontiers in Mechanical Engineering 31 (5) (2019).

doi: https://doi.org/10.3389/fmech.2019.00031

[9] I. Barányi, R. Keresztes, el al., Prediction of Surface Roughness Parametres by New Experimentally Validated Modelling Algorithm under Abrasive Condition, Acta Polytechnica Hungarica 13 (7) (2016) pp. 197-208. doi: https://doi.org/10.12700/APH.13.7.2016.7.11

[10] L. Pokorádi, Introduction to Mathematichal Diagnostics I.: Theoretical Background, Debreceni Müszaki Közlemények VI 1 (2007) pp. 65-80. 